\title{
A Girl Behind a Closed Door
}

\author{
Mengying Yang
}

\section{Interview with Miss Yi Shi's Mother}

Yi Shi, female, born in 1992. Grade III intellectual disability. Has a younger brother. Graduated from a special school-Zhonghua Vocational School, and joined the Sunshine Home in Shanghai in 2013.

Interviewee: Yi Shi's Mother

Interviewer and writer: Mengying Yang

Interview dates: October 27, 2016 and January 4, 2017

Interview place: Yi Shi's home

\section{Couldn't Send Her Away Again}

Q: When did you and your husband get married?

Shi's mother: We got to know each other through one of our friends, and we got married in 1990. I fell pregnant several months after that. Yi Shi was diagnosed with Down syndrome, an inherited problem, when she was born.

Q: How did you feel when your daughter was born?

Shi's mother: I was very glad without any doubt; I was one of the "late marriage and late pregnancy" generation. I didn't even feel the pain when my daughter was born by caesarean, but she looked very different to the other infants, her head was very small, her face was yellow, kind of odd-looking. I'd heard a newborn baby's first cry, just the wailing and no tears, but my daughter did both. Today, I can still see this picture. Before we left the hospital, the doctor realized there was something

M. Yang $(\bowtie)$

East China Normal University, 3663 Zhongshan Bei Ro, Shanghai 200062, China 
wrong with my daughter, but he wasn't sure what it was, so he talked to my husband and suggested that we take her for a proper check-up.

After I'd rested at home for a while, we took her to the Second Military Medical University Hospital and the doctor said she might be a Down syndrome baby. The final diagnosis depended on a chromosome examination. Before this, we didn't know anything about chromosomes, but the result revealed that our daughter had chromosome 21 trisomy syndrome, congenital dementia. The news hit us like a thunderbolt, my husband and I didn't know what we should do, we didn't understand why it had happened to us.

Q: Did your daughter have an IQ test?

Shi's mother: She's grade 3 intellectually disabled, a mild condition. The IQ test was a necessary condition when we applied for a disability badge.

I took Yi Shi myself for the test while my husband went to work. I covered most of the family's domestic duties during that period, I had no choice.

What can you do when you have a disabled child? The mother is the only person who cares for the child. Who else would help raise her? Can you depend on the maternal or paternal grandmothers? Is there anybody who would want to look after a disabled child? Nobody! I didn't have a choice and no support. My husband said: "Except for you and me, nobody likes her." I agreed. As her parents, if we didn't care for her, what could we expect from other people who looked down on her? The people might...

To have a child like her is very frustrating, but we don't have a way out!

Q: What was the first thing you did when you realized she had a disability? Did you want to hide her away or ask relatives for help?

Shi's mother: We didn't do either. We took everything on our own shoulders from the very beginning. It wouldn't have been helpful to ask around my relatives for help; the only thing we could do at that time was to accept the fact and try to solve the problems ourselves. To be honest, it was a very big shock and a difficult period when our daughter was born. I had a normal pregnancy just like every mother, but I had a child like this. I never came to terms with this.

I have a relative who lives in the countryside, when our daughter was 3 or 4 months old, she said: "There are some farmer families who wouldn't mind looking after a child like your daughter if you can pay more than 100 yuan every month." The place she talked about was quite far away, Haimen Town, further than Chongming Island from Shanghai. The foster families didn't know that the children they looked after were Down syndrome babies, but they knew that they had some kind of intellectual problem.

We didn't feel at ease after we sent our daughter to a foster family. After a month or so, my husband suggested that we visit her. All of her clothes were washed and damp hanging on a line in the yard when we arrived, we guessed the family had probably given our daughter a bath and changed her clothes just for our visit. When we saw our daughter, she was sleeping on a round bamboo tray, there was no expression on her face. After she had been with them for over a month, we sent the family a half bag of ground rice, it was still there untouched - at that time, ground rice was the 
only thing she could eat and as a big baby her appetite was good. At lunch time, the family fed my daughter the ground rice we'd given them.

Her quality of life with the foster family upset us a lot, so we told them that my parents had been missing her as an excuse to bring her back home, and we've kept her with us ever since. The foster family came to see us later, but we didn't want to leave our child with them anymore. For us, our daughter might be a disabled child, but she has a right to a life. We can't let her live like those children who stayed with the foster families, a 12-year-old child still living with a dirty, runny nose, for example. We decided to raise her ourselves, it was the best thing for her and for us.

When she was a year and a half old, her dad contacted all of his friends to find some doctors for her. One of them told us to visit a traditional Chinese doctor, 89 years old, who lived in Beijing. The doctor was popular and sounded quite special, and we arranged to meet him just to try him out.

Q: What about this treatment?

Shi's mother: It was hard to tell. His therapy was quite different from normal treatments. It was neither a pill nor an injection, but a kind of pen-shaped needle acupuncture. During the treatment, under the stimulation of this acupuncture pen, my daughter couldn't keep still; it wasn't a very pleasant feeling for her. So I used to take an orange with me and let her suck it while she was treated to calm her down. For me personally, it was a miraculous treatment.

At that time, the apartment we rented was a long way from the doctor's place, so I would travel by bus using a monthly pass. It wasn't an easy journey having to carry my daughter who couldn't walk yet, and we were wearing our thick winter clothes. We'd arrive at the doctor's around 8 or 9 a.m., before he got up, and after he opened the door I had to cook him breakfast, just liked a maid. Do you know what he had? A cup of tea, a piece of fruit and two poached eggs every morning; he always had the same thing. After I cooked his breakfast, I would start testing my daughter's condition with a meter that the doctor had taught me to use.

He charged me 35 yuan for each hour, pretty expensive in those days. My daughter's treatment lasted 2 h every morning, starting with the test.

Later, the doctor would decide what that day's therapy would be depending on the result of the test. After the treatment, he would tell us what to eat and when, for the rest of the day. Following this diet for her everyday wasn't easy at all. But I was determined to do this, and for over half a year I had a life like a poor worker.

In this picture, you can see that my daughter couldn't walk yet; she would stand in a walker I bought for her. In the final month, my mom came to help me because she thought I was working too hard. After half a year, I couldn't see any beneficial effects from the treatment, so we came back home. Later, I broke my back while having a shower one evening at home, I was in pain for a long time, so we didn't go back to Beijing for further treatment.

Q: Did she get any other kind of treatment after that?

Shi's mother: No, we stopped looking for other treatment, because her problem, Down syndrome, is an inherited one. It's a problem with her chromosomes and there is no cure, unlike some diseases that children contract after birth.

$\mathrm{Q}$ : When did your daughter start talking and walking? 
Shi's mother: She was probably able to walk when she was two. I had my second child when she was three, and I've stayed at home to look after both of them since then.

They played together when they were very young; I'd put a sheet on the floor and let them play on that, if I'd left them on the bed they might have had a fall. They were quite interactive and friendly with each other at that time, and their cousin used to take them out together. But their relationship changed after they grew up- they hang out with their own friends - and hardly spend any time together.

We never kept our daughter at home, she went to the nursery and then school when she was the right age just like ordinary children. But at that time, there was no special school for these children, and they couldn't go to a regular nursery either. Her dad found her a small family nursery through the Disabled Person's Federation (DPF) when she was two and half years old. It was small boarding family nursery, just two bedrooms, with only three to five students.

She spent two and half years there and when she was five, she went to the Public General Hospital charity nursery for children with special needs, the first nursery for intellectually disabled children in China. I'm not sure if the nursery is still there, but she spent a year there and then transferred to a special school later.

Compared with other children who have the same condition, Yi Shi was quite lucky to get the chance to go to a special nursery and school, there were few places like this at that time. Frankly, my husband and I had quite progressive thinking compared to parents who were unwilling to allow their disabled children to leave home. We were determined to let her go out as much as we could, because we knew staying at home wouldn't be a good thing for her.

Q: What did the nursery teach the children? Did they have some rehabilitation training?

Shi's mother: Something with dancing and singing, but they didn't have a proper course. I guess they had rehabilitation training or something like that, but I can't be sure, it was a long time ago. The charity nursery was pretty good, the teacher worked like a student's nanny, she looked after everything for the young children.

Q: Has the child ever said anything to you about the nursery?

Shi's mother: No, she was very young at the time; she was just a toddler who couldn't speak much. She could only speak when she reached school age.

Q: Did you feel any pressure when you took young She Yi outside?

Shi's mother: I felt a little stressed at that time because people would look at my daughter's face in a strange way. It certainly felt unpleasant when I was carrying her outside. These days, I'm quite stoical, I'm not aware of what other people do anymore. I just let it go, anyway, we have to face the facts about her condition; and we don't want to keep her at home just because of this. We thought through all of these things and decided that there was no point being secretive about it. Facing up to reality, rather than trying to escape from it, has to be a good thing.

Q: Do you remember any funny stories about little Yi Shi?

Shi's mother: There were many funny things about her, she was a very cute and funny child, you can see her childhood through our family pictures (takes out some pictures). You can see that she was completely different to ordinary children in this 
picture, which was taken around the time she was born. It was the way she looked at that time. We didn't have too many toys but some miniature cars and dolls. That's my cousin playing with my daughter (points at a picture). She looks quite cute in those old pictures, but I can't recall any details about her everyday behavior, it was a long time ago.

\section{Starts School at the Right Age and Never Falls Behind}

\section{Q: Where did Yi Shi go to school?}

Shi's mother: She studied at a special school in Shanghai, which was in the same building as our apartment, on the ground floor. Her schooling was the same as any ordinary child, from nursery and pre-school to special school, and she never fell behind the children her own age. She went to a special school at six and followed the 9 -year compulsory education. Then, she passed an interview fora special vocational school and transferred there after she graduated.

Q: Did she like the school?

Shi's mother: Yes, she enjoyed her school life. She went to school by herself and was one of the class committee members. She was the student leader and was involved with class management. A student guardian had daily duties and Yi Shi represented her class. She was very open and active, and she could flatter her teachers, always giving them a hug or a kiss. She was popular with both her classmates and the teachers, everybody liked her. Being coy is a kind of natural behavior for little girls but not for boys, her kisses would always soften up my husband straight away.

Q: Did she like to talk about her school life with you?

Shi's mother: No, she didn't say very much. But the school was very close to our place, I could see the campus through the window. It was convenient and made things very easy to communicate with her teachers. They had extracurricular activities all the time, my favorite one was their model show and Yi Shi won a medal for that. The teachers were very clever and had very skillful hands; they made all kinds of clothes for the children with cartons and used paper. They were attentive, paying a lot of attention to making costumes for the children; they were full of smart ideas, it would have been impossible for me to do things like this.

The students had a show and performance with their handmade costumes, with the parents as their audience. I rarely missed this kind of school activity if they invited me, it was about sharing nice times with the children and a good way to show our support at the same time. I would take some pictures for her during the show, but I didn't print most of them. Back then, documenting a child's life in photographs wasn't very popular. Apart from the events with students and parents, I didn't know very much about the school's business. It wasn't possible to learn about the school through my daughter.

She wasn't very different from the other children of school age, nothing stood out typically. I remember the teacher saying she wasn't a difficult student, but she had a stubborn character, and would refuse to do some dance movements that she didn't 
like. The teachers were nice people who had plenty of patience with the students, they never got angry. (She takes out another picture) Take a look, it's a class picture from back then. It was a big group; the maximum was less than 20 students. In a regular school class, there might be a few dozen students, but for a special school teacher this would be too many. The last thing is special school students are different from ordinary children; you have to reduce your expectations of what they can learn and achieve in their exams. Compared with ordinary students, the exam results mean much less to them, learning as much as they can is more important.

Q: Did any of her classmates visit your place?

Shi's mother: Yes, of course. My daughter's classmates often came to our place, because we lived so close. Some of her classmates lived far away from the school; some of them even came from Chuansha, a town some way away.

One time, one of her classmates went off with my wallet; it was quite a shock, and I had to stop them coming after that. She didn't have many good friends at school, but she used to mention a boy quite often. He went back to his hometown after he graduated and lost touch with us. Years ago, we heard he'd drowned in a river. What a shame! He was my daughter's only good friend.

Q: Did you give Yi Shi family tutorials very often?

Shi's mother: Rarely; I'd explain some questions if she needed my help. They had Chinese, mathematics, music, and PE at school, but the learning requirements for them were far less than a regular school. For children like her, enjoying life is more important than other things like studying. It's a different story for my son. I let the teacher deal with my daughter's studies.

Q: Do you remember any impressive things that she did at school?

Shi's mother: She was a warm-hearted child and she never hesitated to help classmates who needed help. She was always willing to help and had a very good relationship with all her classmates.

She used to be a part of the school's charity events. They would visit an old people's home and perform for the elderly residents. She also gave handmade cards and cut flowers to her teachers on Teacher's Day. She was quite a conscientious child (see Fig. 1).

Q: Where did she go after she graduated?

Shi's mother: She joined the Zhonghua Vocational School after she graduated from the Shanghai Special School.

Q: Did they have an entrance exam at the vocational school?

Shi's mother: No, they only needed to pass one-to-one interview. Not everyone who had studied at the special school could go on to the vocational school, only the students who were able to pass the interview. The interview wasn't any different from a normal interview; the teachers sat in the classroom and waited for the interviewee to come in, then asked her some personal questions and they had some simple conversations. She didn't have any problem with speaking at that time, she was quite active and open; otherwise, she wouldn't be able to pass that interview today, she is much worse than she was back then.

Q: Did Yi Shi choose her major? 

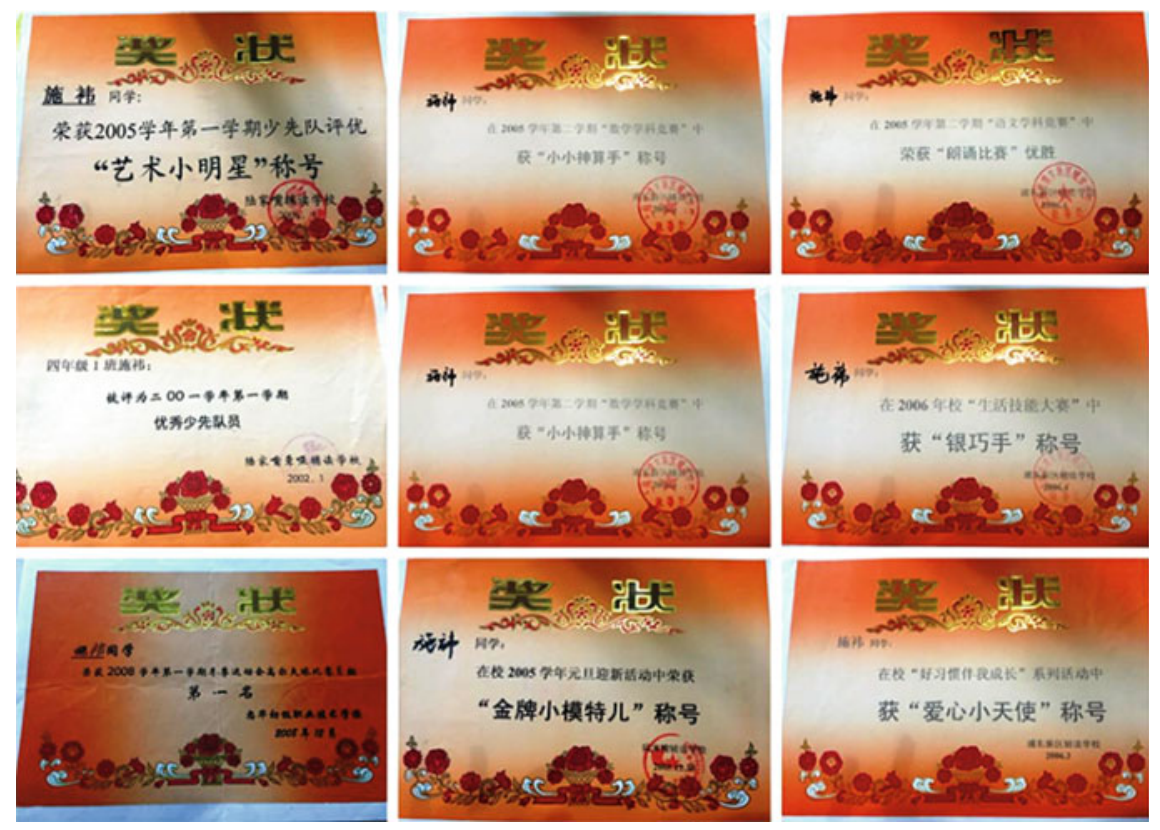

Fig. 1 Certificates of merit Yi Shi won at school

Shi's mother: No, her major was decided by the school; the teacher chose the most suitable subject for the students based on their condition, capability, and interests. The teachers knew their students well, because the school leader was also the leader of the Shanghai Special School. They thought cooking was a good choice for a young girl like her.

Q: Did she study cooking for all 3 years?

Shi's mother: That's right. She wouldn't have been able to do other jobs like a cashier or a waitress, so cooking was the best choice. Frankly, I didn't pay very much attention to this kind of thing, because I never expected too much from her, so I let her enjoy her days, that was the main thing for me.

She grew up quite a lot over the 3 years. She used to bring home different dishes every day depending on what dish they were cooking that day. Sometimes, she brought home handmade biscuits for us. The parents paid for the cooking materials every year because it was impossible for the school to find this money. In addition to cooking skills, the teacher also taught them how to select meat and vegetables.

Q: Did she also like to cook at home?

Shi's mother: She cooked at home in the beginning; she was able to cook fried cucumber and egg, fried tomato and egg, that kind of dish, but her favorite dish was fried tomato and egg. She would also help to tidy up at home. My husband and I were so pleased with her achievements. 
I'm no different from any other conscientious parent; I like to do housework for the family. After she got used to being looked after by me, she stopped cooking or cleaning and stayed in her own room with the door closed.

The good thing about my daughter is she'll never refuse to help me if I ask her to. Sometimes, when she comes into the kitchen, I have a little fun with her, letting her cook, just stirring food in the pan. She's willing to clean up the house if I ask for help; anyway, she has quite a positive attitude to housework. But she won't do anything if you don't ask her, just like most ordinary children. So she isn't bad with household duties.

Q: Why did you send her to the vocational school? So she could find a job afterwards?

Shi's mother: We wanted her to keep learning something, going to school was ideal. What else could we do for her? What kind of work could she do in the future? There was nothing we could do for her but let her learn as much as she could. Some families with disabled children never let them go to school and leave them illiterate. Other families keep their children at home all the time. Both of these things are very bad for the child's development. But our daughter's experience was the opposite; I mentioned her childhood and pace of study was just the same as ordinary children. At least now she knows quite a lot of characters and is able to read properly. She never had reading problems like uneducated children. And she likes handwriting very much, her writing is quite beautiful. She wouldn't have been able to do these things if we hadn't let her go to school.

Q: What did Yi Shi think about studying at the vocational school?

Shi's mother: She didn't disagree about going to the vocational school; actually, she liked to go. It was a long journey from our place to the school, which was on the South Ferry, Pusan Road. Before she knew how to get there herself, I would walk her around until she got used to the route. Independent travel between home and school was a school requirement for the students, because the teacher said it should be a very basic thing for them to do. If they were really unable to do this, it might be a waste of time studying there. She also worked for a year after she graduated, the workplace was on the Longyang Road, quite a long way for her as well. She had to take a bus to get there and then walk some distance before catching the bus back, but she had no problem with this route at all. I have to say she was quite independent.

Q: Do you think Yi Shi was successful at her studies?

Shi's mother: She was pretty good. She started primary school when she was almost 6 years old, the same as an ordinary child. Actually, her birthday is later in the year, in August, she almost didn't go to school because of that slightly later birth date. After that, she did 9 years of compulsory education and then 3 years at vocational school. It was quite a good place for her, she met some nice teachers who liked her very much, and treated her very well, too.

But now, she's gone into herself, she isn't interested in talking to other people anymore. I really don't understand why, others have commented about this, some young girls can become too shy to talk when they grow up.

Q: When did Yi Shi start to become independent in life skills? 
Shi's mother: When she was very young. I taught both of my children to take baths by themselves when they were very young. If they couldn't wash themselves properly by this time, I'd make them take another shower until they learned how to do it. Some children at the Sunshine Home who are older than my daughter still need their mother's help with bathing. Some students are still driven to school by their parents, even though they could walk by themselves. I really don't think I need to worry about her so much and I'm determined that she does as much as she can: I have to let it go. Otherwise, what would happen when the parents get too old to help them with these things? To be honest, I'm getting old now, I can't say how much longer I'll be able to look after her.

I also taught her to hand wash her underwear, she learned from watching and practicing. I told her that her underwear is the only thing she mustn't put in the washing machine. I won't wash the stuff for her, but I still check it after she's washed it. Now, she's independent enough and she'll be absolutely fine as long as you cook for her. I'll teach her to cook sometime. Sometimes, these days, I like to let her wash some plates and she usually does a good job.

Another thing is letting her buy things for herself. She's pretty good at shopping already. She's been to most of the shops nearby by herself-my husband and I know the owners well-we usually give her some cash to buy small things she needs like notebooks or pens. But she can't go to the supermarket on her own yet. I'm usually quite relaxed with my daughter; I let her do everything she can. I treat my son in the same way; he became quite independent when he was in his second year at school. Both of them went to school on their own when they were quite young, crossing the road by themselves. I never picked them up like some parents do, not when they were able to travel by themselves. As a parent, I have to understand when the time is right to let them go.

\section{A Special Olympics Dancer with Down Syndrome}

(The mother takes out Yi Shi's pictures from when she was young.)

S's mother (holds the picture of a time when her daughter was a presenter in a show): This is a picture of my daughter presenting a show with her teacher; she looked very different in those days. (Takes out another picture) It's a picture with Bajia Pu, a winner of the first season's My Hero. ${ }^{1}$ Both of them were actors in the Special Olympic propaganda film in 2007. Renliang Qiao, another boy from $M y$ Hero, who died recently, was there with them as well. At that time, Yi Shi was a warm and active girl; she greeted the boys from My Hero without any prompting and had pictures taken with them. She spoke to them by herself: "Big brothers, would you like to have your photo taken with me?" Then, she took these pictures. (Finds

\footnotetext{
${ }^{1}$ My Hero was a popular national TV singing competition for boys, which was broadcast by Dragon TV in 2006 and 2007.
} 
another picture) It's Meili Qiao, who was very popular as the Goodwill Ambassador of Special Olympics.

When she became involved in the Special Olympics propaganda film, I was my daughter's assistant during the filming. The director would call me anytime they had to film a scene with my daughter. We followed the teacher's guide and were able to visit different places every day. It took quite a long time to make the film, sometimes we had to stay at the television station until late, and it was a very tiring job for me following them all over the place in that hot weather. This picture was taken from the ninth floor of the station.

Please feel free to copy these pictures if you like. We don't have anything to hide with our daughter, facts are facts. We have so many pictures of her, most of the pictures that you are looking at were taken in 2007, almost 10 years ago. But now she's become a very introverted girl, I really can't do anything with her.

Q: Who went to the film recording with the boys from My Hero? All of Yi Shi's classmates or just the athletes from Special Olympics?

Shi's mother: There were only three or four children who were picked by the director's team. But I don't know what the selection criteria were, I guess because those children were good at dancing?

Q: Did Yi Shi take part in some of the Special Olympic games at that time?

Shi's mother: No, she didn't. She was too fat for sports and she only attended the Closing Ceremony. She was chosen to be a part of the ceremony, because the director of the program was determined to let her be there. She almost didn't make it, because she was too stubborn and wouldn't follow the dance teacher's instructions.

Q: Why did the director insist on having her in the show?

Shi's mother: I didn't know very much about this at the time and only heard the story after she was transferred to the vocational school. Later, I was a member of the parent's association at the school and I attended school meetings. One time, I chatted with the school leader who told me the story. He said my daughter's disobedience during the practice session made the dance teacher unhappy and she was thinking of dropping my daughter. But the teacher withdrew her decision when the director said he wanted my daughter to be involved. Yi Shi was the only child in that big group of children who got a close-up shot during the live broadcast of the Closing Ceremony. She was also the only child with a close-up image in the autograph book from the Shanghai Special Olympics.

Q: Well, it sounds like she was a stubborn girl, but did she want to go to the performance?

Shi's mother: She's a hard-nosed child and hardly listens to other people, but she's much better with her family. She usually listens to us, her parents. She ignored her grandma completely last week when we visited her. But she wouldn't do that to my husband and me.

Q: How long was the Closing Ceremony practice session?

Shi's mother: I forget how long; we were waiting fora phone call from the director of the team all the time. They had a daily shuttle service for rehearsals, but the parents weren't allowed to go to the rehearsals or the final ceremony, so we could only watch the TV program. The main rehearsal was for the dance, my daughter didn't have any 
problems with that, and she liked to dance very much. She was the school's leader for the people's radio calisthenics every day.

She's still a big fan of dance, even now. She has a talent with musicals; for example, she danced quite a complex dance using hand language, some movements were impossible even for the adults to remember, but my daughter remembered all the sequences. Children like her can be very receptive to music and have a special ability and interest in it. Zhouzhou, an exceptionally talented conductor, is a Down syndrome boy as well; he's a better conductor than many normal musicians.

Q: Did you notice any change in your daughter after she became involved with Special Olympics?

Shi's mother: Not really, it was a special and joyful experience for her. To enjoy the experience was the most important thing; she was very happy during the event. The teachers were thoughtful and caring, and, for the parents, it was a valuable opportunity to meet each other. It was a wonderful experience for everybody involved, and to be part of Special Olympics was a wonderful memory for her. In addition to this, she attended the summer camp which hosted Special Olympics last year, the International Special Olympics East Asia Camp Shriver in 2015, which took place near the Stadium in Yangpu District.

Q: Do you remember what kind of event it was?

Shi's mother: A Special Olympics event, I have some pictures of it. It was a summer camp for children with intellectual disabilities. They didn't have to have proper training; the children could just play games together. My daughter joined in throwing balls and running races.

Have a look at these pictures (points to a picture). It's a picture of the unified walk, where the players use ropes made from newspaper to tie their legs together and walk. The fastest team is the winner. They are helped by volunteers. It was a week-long international camp; the children came from various places and countries. We went to the camp every day, my daughter and the other children also had two camp uniforms. There weren't any professional competitions, just some games and events to allow the children to enjoy group life and get closer to the outside world.

(The mother shows the interviewer an extract from a video of Yi Shi taking part in a shuttle run game. She's trying very hard and concentrating on the game. At the same time, the mother is cheering for her all the time.)

Q: Yi Shi plays many different games, which one does she play the best?

Shi's mother: To be honest, she isn't an active person at all. I haven't noticed any game that she's typically good at. She doesn't have a lot of sporting talent.

\section{Her Autism Gradually Became More Apparent}

Shi's mother: Yi Shi got a job through a friend's recommendation at the Sunshine Workshop in the Pudong New Area after she graduated. That workplace doesn't belong to our subdistrict, it's a municipal charity institute, I guess. It's a workplace for people who have a range of disabilities, intellectually disabled, physically disabled, 
or dwarfism and blindness, all kinds of disabled people, you name them. She cried for the first several days before she got used to the place, but she started to enjoy it as time went by.

Q: What did they do there?

Shi's mother: I don't know much about what they did, because the place wasn't convenient for parents. If you insisted on staying, you had to wear special slippers. I didn't like this place and didn't go there very often, but Yi Shi talked about their work with me; basically, they did some simple jobs like making bibs, packing disposable chopsticks, folding gift bags, and wrapping soaps. These children can't do anything too complex and this simple work is pretty good for them. You don't know about people with intellectual disabilities as much as we do, some people are in a much worse condition than my daughter. As parents of disabled children, we are quite miserable, the chance of giving birth to a child like this isn't common, but if you do have one, then you have to look after this young life. For my husband and me, we really wanted to give her a happy and carefree life.

Q: What is the Sunshine Workshop?

Shi's mother: It's a kind of charity institute, an interim place for these children, but they can't stay longer than 2 years. The workers have to be recommended for a proper job or quit within the 2-year period. My daughter wasn't really employable, so she didn't get a job recommendation, but some of the children got a pretty good job. At the Sunshine Home there are some children who are more independent than my daughter. It would have been impossible for my daughter to find a proper job before they did.

Q: What was her relationship like with her colleagues at the workplace?

Shi's mother: She had a pretty good relationship with them, harmonious enough.

Q: Do you know what kind of work your daughter wants to do?

Shi's mother: Her condition won't allow her to do too many things; enjoying her life is the most important thing for her. She doesn't want to work; at least she never mentions a desire to work. Her favorite thing is staying in her room without doing anything. These days, she has become quite big, a little fat pig! You'll be surprised by her size when you see her (laughs away).

The teacher told her she had to quit her job after she'd worked there for a year. Perhaps she was too young and didn't have enough ability for that kind of work. So she came back home after that. I didn't pay enough attention to her during that special period. It was my fault, I was very busy looking after older family members and two other children in the family.

It was a very difficult time for her. She stayed at home all the time, no friends but herself, it wasn't a pleasant experience. Later, she was probably depressed, a kind of mental problem, and, little by little, she isolated herself. I took her to see a doctor, but the doctor said there was no evident sickness. He couldn't tell what her problems were precisely, but that it was probably related to her intellectual disability.

She became a different person, it was the biggest change in her life: now, she doesn't care about things anymore, she's stopped talking to people. Even her personality is totally different from before. It used to be my son who always hid away when guests came around, my daughter was never shy with strangers. She was a very 
attentive hostess, liked to make tea for the guests and chatted with them. But these days, their characters have completely swapped around.

She used to be a very open little girl, chatting and playing with people very much. When she was the student leader of her class, she enjoyed it when her classmates followed her orders, even if she didn't understand what managing a class was really about, she just played at that role. But at least she was doing something at that time. She never stopped talking when she went out with her dad on the bus. I used to get quite annoyed with her and tried to stop her talking too much. Now, she won't speak a word even if you asked.

To be isolated in this community is a terrible thing for people; even harder for a child like her. People need to communicate with their friends, but my daughter is alone, she has only herself. What could we do for her? My husband and I tried to take on the role of a friend and chat with her from time to time, but she would never join in. When she got home her dad would say: "Yi Shi, come and sit next to me, let's chat," but she would walk into her room and close the door, like she doesn't care for us at all. She will stand up immediately and shut the door if I forget to close it after I leave her room. I really don't know how to deal with her. She just doesn't want to communicate with people anymore. When she is at home she just stays in her own room, listening to music, writing characters. She likes writing very much, she is always writing down words from books.

\section{At the Sunshine Home She Could Engage with Society}

Shi's mother: I discussed this with a teacher at the Sunshine Home and decided to send her there hoping to change her condition, being with classmates and chatting with them has to be a good thing for her. It wasn't a good experience for her staying at home for so long.

Q: When did she join the Sunshine Home?

Shi's mother: She's been there almost 3 years. The place isn't very close by; it takes her half an hour to walk there. She walks to the home by herself, I only went with her the first few days. Their class usually finishes around 3 p.m.; sometimes they can leave a bit earlier.

Q: How did you teach her to cross the road?

Shi's mother: It wasn't complicated for her; as we crossed the road together, I just explained what she had to do and showed her how to do it. I used the same method to teach her to how walk to the home by herself: I let her follow me all the way, told her where to turn, where to go straight, to be careful at the traffic lights and walk through on the right light. She needed a week, more or less, to learn this. The thing you have to remember is to be very patient with her. I don't worry about letting her walk to the home on her own. When she worked at the Sunshine Workshop, which was much farther away, she had to take a bus for five or six stops. If she could do that journey, walking to the home would not be difficult for her. 
On the day we went to register, the teacher asked me if my daughter needed her parents to bring her or not, I said she will go to school by herself once I've taught her the route. It would have taken too much time to walk her to school every day, I wouldn't get enough time to do my housework at all, because they finish early.

Q: How long does she need to walk to the Sunshine Home?

Shi's mother: She's a slow walker, it's about a 20-min walk, more or less. From our place, there are two ways to walk from the community to the home; one way is shorter than the other but she has to cross a footbridge. She chooses her route at random, I don't mind which she takes and I think the walk is good exercise.

Q: Has anything ever happened to her during her journey that's made you worry?

Shi's mother: Not really. She had an old-fashioned mobile phone before, but she lost it. Later her dad bought her a new smart phone, but she doesn't like it, and she doesn't know how to use it either. The old one, a clamshell phone, was her favorite. These days, she doesn't use a phone anymore. But when she was working at the Sunshine Workshop, she had quite a lot of fun with her phone. She used to call me on her way back home to let me know she was on her way back, but she doesn't use her phone anymore, she never carries it with her.

Q: When she has to go to the Sunshine Home, does she get up by herself or wake up with you in the morning?

Shi's mother: It's probably half and half, but she gets up without my "morning call" these days. She might be a little bit lazier than normal from time to time, but she's been pretty good recently. She finishes her morning work before 8 a.m., and has her breakfast afterwards. I only need to cook her breakfast in the morning, nothing else. I have to remind her to leave home on time, because she doesn't have a good sense of time, and she can't read a clock. She's also a bit of a slow person.

She usually goes to bed around 9.30 to 10 p.m., but I have to start my "bedtime call reminder" from half past nine, and keep telling her: "Yi Shi, it's your bedtime, get on with it."

Q: What does she usually do at the Sunshine Home?

Shi's mother: The teachers get them to do all sorts of things, making boxes, making a cat-shaped phone case with beads, some children are really good at it; playing table tennis and baking. Sometimes she likes to bring back home the biscuits she made in class and wants me to try them. I'd ask her: "Did you make them?" and she'd reply: "Mom, the teacher taught me to make them." I wish I'd sent her to the Sunshine Home earlier! The teachers are very nice and they arrange all kinds of activities and events to create social opportunities for the children. It's quite important for these children, most of them are older than my daughter, but they can only stay at the home and don't have any other place to go.

Q: Do you have any of Yi Shi's handicrafts that she's made at the Sunshine Home?

Shi's mother: I don't keep many of them these days, but I used to keep quite a few. For example, I kept her early paintings when she'd just started to learn painting, but I stopped collecting them, there were so many. She had lots of balloons, but I threw them away after a while. I kept some of her handmade flowers. She said she made them by herself in the class, but they almost seem too pretty to be have been made by her. I guess her teacher helped her lots with these flowers. Even though she didn't 
make them herself, they're still a special gift from my daughter, they made me very pleased. Yi Shi is a very caring child; she would make birthday cards for the family when she was a student. She used to make me a hand-drawn card and sing for me on Mother's Day. As her parent, I'm so pleased she's such a grateful person.

Q: Does Yi Shi receive a salary from the Sunshine Home?

Shi's mother: No she doesn't, but she had a salary in her first job.

Q: Was she very happy when she received the first month's pay?

Shi's mother: It was hard to tell, because she doesn't have the same concept of happiness like other people, she also doesn't understand the value of money, especially when they receive the salary on a bankcard.

We don't use her money; her dad saves all of it just in case she needs it one day. While she's living with us, she doesn't need money, she doesn't need to buy anything here, or at the Sunshine Home.

My daughter's sense of numbers was very poor, but it's getting better now. She only liked to use 1-yuan coins and she didn't want to use any notes. At least now, she understands what 10- and 20-yuan notes are, but if the note is bigger than that she won't use them, she can't understand their value. She won't know how much change she should get if you let her go shopping with a 100-yuan note.

Every child has his/her own characteristics; some like mathematics, some like my daughter are musical. I usually tell her which shop she needs to go to before I give her any money to buy things - all the local stores know us - they won't cheat my girl. Let me speak frankly, if there's an outsider in the community who isn't very nice, he would only give her 1 yuan of change after she bought a 1-yuan bottle of water with a 20-yuan note; my daughter wouldn't know she'd been cheated. I tried to teach her something about money a while ago, to recognize different currency by playing with different notes together. Now, she knows the notes, but she can't add up the numbers, so she still doesn't feel confident using a 100-yuan note. It took me quite some time to teach her, she just isn't sensitive to numbers at all, so I stopped when my patience ran out. might have to try again when she needs to deal with money more often.

Q: Does Yi Shi talk a lot at the Sunshine Home?

Shi's mother: No, she doesn't talk at all. She probably talks more at home than at the Sunshine Home, but I can't let her stay at home on her own anymore. She just sits there and doesn't talk to anybody even though I'm always telling her that she should communicate with the other students, talk more and try to make some friends. She usually says yes to me, but I know my advice doesn't work. I have to keep reminding her. It's not just my daughter, the other children are the same. They are not like their parents who are used to socializing with people and making conversation, these children find it hard to make conversation unless others talk to them in the first place.

I've been to their place and seen some very active children who don't look like they have any kind of intellectual problems. They look normal, good talkers and they have great abilities, but they only have learning difficulties. They're so different from my daughter, her face tells you everything. There's a boy in her class who has to do lots of housework every day, he has to mop the floor and hand wash summer clothes. One time, his mother told him: "You aren't allowed to go to the home until you finish the housework." 
I volunteer for some Sunshine Home events from time to time; that's how I got to know more about these children. There's another boy who has a paralyzed mother to look after, he has to get up at six, sort out the house, and make breakfast for his mother before he leaves for the Sunshine Home. When he gets home, he has to do other things for his mother. What a difficult life! But he's always positive and even knows quite a lot about healthy living; he told me when it's the right time to have certain herbal teas. He looks exactly the same as a person without disability. People used to say poor children mature early, this boy is certainly one of them.

Last month, on the 17th, the Sunshine Home had a big event. Everybody was told to be there on time, but one child didn't make it. The teacher told us his story afterwards. This boy has a paralyzed mother and a very ill father to look after. The family's life isn't easy at all, and the boy has to take responsibility for looking after his parents. Before the event, he asked the teacher for leave, because he had to stay at home and care for his parents. What a good boy, that would be impossible even for lots of ordinary children (see Fig. 2).

Q: Does your daughter like to go to the Sunshine Home?

Shi's mother: She doesn't have an opinion, but she would listen to you. I told her: "The teacher might criticize you if you don't go to the home," then she started to go there. It's unusual for her to ask us what she should do except when she has a very strong interest in something. For example, she likes handwriting very much and she'll ask her dad for paper, pen, and a notebook if she runs out. If she asks us to buy things she likes, we usually give her some coins and let her buy them in the shops herself. But she won't ask for more than that.

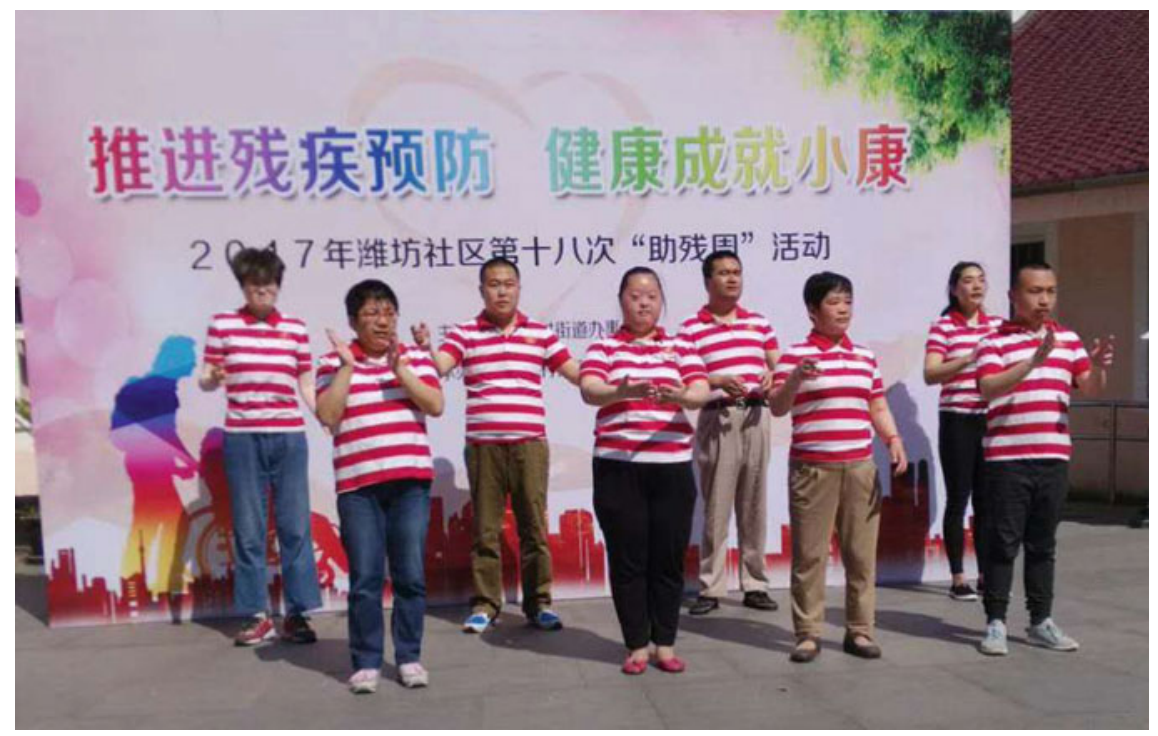

Fig. 2 Yi Shi (front row left two) performing in the community 
Q: Last time when I met her at the Sunshine Home, I asked her which she preferred between her own home and the Sunshine Home; she said she preferred to stay at home.

Shi's mother: No, it's not possible, I can't let her stay at home. When she was staying at home all the time, she just shut herself in her room and hardly went out. When she got used to that kind of lifestyle, she even had her meals in her room. She would shut the door all the time and never talk to anybody. My husband and I had would have to force her to stay in the living room with us, to write her characters in front of us, too. This isolated lifestyle wasn't good for her at all.

Q: What does Yi Shi usually do at home?

Shi's mother: She usually listens to music, dances a little bit if she's in the right mood, or just sits there, being lazy. She didn't do any activities and became worse after she put on a lot of weight. Now, she's become a short, fat girl (takes out some of Yi Shi's old pictures). She looks good in this picture, but she's already getting bigger, and now she's much bigger. We worry about her a lot. After school they don't need to do any homework or practice sports, they just eat and sleep.

\section{A Dedicated Mother Who Becomes a Volunteer}

\section{Q: Did you get any help from the community?}

Shi's mother: The community doesn't do very much, but the subdistrict office helps us more. In this subdistrict, there are five disabled people's associations: for intellectually disabled people, mentally ill, physically handicapped, blind, and deafmute people. I'm working for children with intellectual disabilities that live in the subdistrict. The official asked me to join their volunteer team and I thought it would be a good thing to do and joined them. Later, the official asked me to work with intellectually disabled children, those with the same condition as my daughter. I thought this would be a good way to encourage families to deal with the same problems together, so I said agreed to help.

Every year our association receives some funding from the subdistrict office and I usually arrange some events for the children every quarter based on the budget. Generally speaking, our group events are about singing, playing games, having parties, or doing puzzles together. At the end of the year, we have a group day trip as well, but it can't be anything too expensive or too far away because the budget is tight. Last time, I took the group on a day trip to Gongqing Forest Park. In December, some people from the Association of Persons with Psychiatric Disability and their Relatives joined us for a day trip; we visited Disney Town, not Disneyland Park because our budget wouldn't cover that. Here's the group pictures from that trip, I usually take some pictures of the children and print them out and give them to the children as a gift.

There are over 20 children in our group, the mildly disabled children came on the day trip alone but the parents of the severely disabled children would accompany them. I usually pay for the parents' tickets and buy a meal for everybody afterwards. We have to work out the best way to use our limited budget so the children and their 
families feel our care and love. New Year is coming and I'm thinking about what kind of little gifts I could afford for them. This association work is on top of my busy housework and everyday life, I'm so busy. We will probably take the children out again next month; going away together is a great way to learn about the outside world. They are just poor children and I like to do these things to help them.

Q: Do you have any volunteers who go out with you?

Shi's mother: No, we don't have volunteers for the day trips, this is a "family tour," a time for parents to share with their children. To be honest, letting the parents come along to the events is a better way of looking after the children in the group. I can't take responsibility if any of the children get lost during the trip, so it's better for the parents to be there. Safety is very important.

Just this week, the district DPF office arranged a day trip for some of the children and their families, and all of the adults were terribly worried when a boy went missing. The parents looked everywhere for him. I was so anxious, and the leader of the organizers was so worried she cried. We called an emergency number for the police search group. They sent a big group and looked everywhere for him. We even used the social media, WeChat, to share missing information about the boy online.

Finally, around eight that evening, the boy was found at home. He's an interesting boy, he walked for over $4 \mathrm{~h}$ and arrived home with blisters on his feet. The only mistake he made was he didn't tell anybody, even his parents, where he was going. What a scary story! Every child is a special treasure for his or her family, no matter what kind of condition he or she is in, nobody can afford to lose them, especially when they're under your charge. Special children aren't safety conscious and need to be more careful, you never know what will happen, and any safety precaution is never too much.

\section{A Happy Family Enjoying Life}

\section{Q: How old was Yi Shi when you quit your job?}

Shi's mother: Actually, I didn't quit my job, I had a redundancy offer in 2005. I worked until the very last moment of my first pregnancy, it's difficult working when you're pregnant. After my daughter's birth, I didn't have anybody to help with babysitting, because of her condition. I had to ask my boss for leave. The boss approved because of the special family situation.

I never went back after that. In the beginning, I was suspended without pay until I was told to go back to work. I didn't want to take the redundancy offer at first, but one of my good friends, who was also a colleague told me this offer was a better deal. So, both of us took the same deal together. After that, I became a housewife and spent all my time looking after the family.

I started taking some part-time jobs from time to time after my children grew up, but I couldn't do this for long because the children usually finished school earlier than me. Especially my daughter, she would leave the special school and get home 
around 3 p.m. I didn't dare give my daughter the house keys at her age, so somebody had to be home for her.

Now I don't need to worry about my daughter in the same way. Yi Shi has her own keys and she comes back anytime she needs to. To be honest, I sacrificed a lot for my daughter, but it's the only thing I could do.

She's my daughter and I have to take responsibility for her. My life's very hard especially after I had my son.

Q: What does your husband do?

Shi's mother: He worked at the Shanghai Oil Refinery until he was quite old, and then changed his job. Now he works in Hangzhou but only comes back home once a week.

Q: How about the relationship between Yi Shi and her dad?

Shi's mother: They're very close; she's really close to her dad. The first thing my husband does when he gets back home is gives my daughter a kiss. If you ask her who is your favorite parent, she will always tell you she likes both of us equally, but everybody can tell that she's much closer to her dad. My husband only comes back home once a week, but he usually spends his Sundays taking our daughter out somewhere. If he's going to a social event, like a group meal or afternoon tea, my daughter always goes with him. My son doesn't go to these events with him at all. She likes to go out with her dad as well, she enjoys the food and their company, and never disturbs him and his friends.

One time, on the way back home from the supermarket when we were passing a Cat Cafe, she told me she'd been there. I said to her: "No way, even I haven't been there yet." Later, I mentioned this to my husband and he said they had been to the cafe together when he had a business meeting there. He ordered a cake for her and let her sit next to him. You see, she has quite a happy life.

Actually, I love my daughter very much as well, but I can get loud when I'm angry and lose my temper; she probably finds me a bit frightening. When her dad gets back home, it's a completely different story, she likes to call him: "Dad, Dad...," all the time, she's very close to my husband. But she never kisses me! Sometimes, I make a joke with my husband: "Lucky you! I've had such a hard week and I don't get a kiss from my daughter." Even now, she never forgets to give her dad a good-bye kiss before he goes back to work. My son is closer to me.

Q: Do you ever disagree about the children's education with your husband?

Shi's mother: No, we never disagreed with each other about this issue; in fact, we always agree about children's issues. We're a happy family, we never argue with each other, especially my husband and me, and we never argue about the children. My husband is usually busy at work supporting the family, and I focus on caring for the family and children. If I'm ever concerned about our children I'll discuss it with him. My husband trusts me and lets me deal with all kinds of issues about the children whatever it is, family or school. He's never been to a parent's meeting since they were little.

Q: So your husband doesn't share the caring duties?

Shi's mother: No, he's too busy at work, the whole family lives on his income. It's understandable, isn't it? We share the family duties, he earns the money for the 
family and I stay at home and look after them. I didn't have a choice, somebody had to make a sacrifice for the child.

She's our own child and we have a duty to look after her; whatever her condition is, I have to take care of her and raise her. My husband also says we shouldn't expect too much from her in the future, but let her enjoy her life.

Q: How many years older is Yi Shi than her brother?

Shi's mother: She's 3 years older.

Q: So you had to look after two children when Yi Shi was 3 years old-was there anything particular that you remember about that time?

Shi's mother: The biggest feeling from that time would be "busy." I never got my own free time, I was always very busy. It was very difficult. My daughter is different from normal children; she was completely helpless when she was 3 years old. I didn't get much help bringing them up, except for the time my mother-in-law helped me to look after my newborn son for a month. What an exhausting life!

When they were little, we lived in a one-bedroom room apartment. I had to close the doors and windows all the time just in case one of the children hurt themselves. There was a big bed and a cabinet in the room and if I had to cook or do housework, the only way to stop them crawling off the bed was to put lots of things around the edge. Bringing up my daughter is the best thing I've done in what's been a difficult life.

To be honest, having the second child was a good thing for us even though most families in our group are one-child families, although now I'm relieved that they've both grown up.

Q: What were your thoughts before you had a second child?

Shi's mother: My husband and I are healthy people-we aren't related in any way definitely - our families didn't live in the same area, one was in the Shanghai Railway Station area, the other came from Gaoqiao Town: how could we have had a disabled child? We thought about this again and again and then decided to have another child.

It might be even harder to look after two children, but who would we depend on when we got old if we only have our daughter? It's a serious problem. The one-child families in our group are worrying about who will care for them in their old age and for the future of their children. Their family problems are also a social problem, most of the one-child families choose not to have another child because they worry that the second child might also be unhealthy, and for some families who decided to have another child, this happened. There are two pairs of twins who are siblings who attended the same school as my daughter, all of them are disabled children. Their parents didn't dare to have any more children after that. When this kind of thing happens, parents are helpless and desperate.

Q: How do you communicate with your children?

Shi's mother: I don't communicate with them specifically; I just tell them what they should to know and that depends on their different needs. I used to pay most attention to my son's study, but I didn't need to do the same thing for my daughter.

Q: How long did your children play together? 
Shi's mother: They were quite close when they were little, but after my son went to nursery they played together less and less. Anyway, one is a boy and the other is a girl, they're different. We moved to this apartment with more rooms when my son started at the nursery; they were older and we could give them their own rooms. Since then, they haven't had very much to say to each other. The brother is different from his older sister, they can't really keep each other company, they like very different toys. You can't let a boy play with dolls.

Q: Does Yi Shi talk to her brother often?

Shi's mother: Very rarely, my son doesn't talk to her very much either. My husband said things might be different if our second child had been a daughter too, at least Yi Shi would have more things to talk about with her. But now, my children don't have anything to chat about together. My son usually stays in his room and reads or does something else when he's home. He isn't bad towards her, even though they don't talk very much. When we eat at home he always lets his sister have her favorite dish first.

Sometimes, when they were younger, if my daughter liked her brother's notebook, and she didn't dare ask him herself, she used to ask me to borrow it for her. My son would never say no if his sister wanted his stuff. When they were bigger, if my husband and I couldn't cook for them, my son would cook for my daughter and keep her company at home. But they really don't talk to each other very much.

My daughter has changed quite a lot. She has become more autistic; she shuts herself down and stops talking to people, not only with my son, but also with my husband and me. She might respond once if you speak to her ten times.

A couple of days ago, on the way to a district event, I tried really hard to make conversation with her. I kept asking: "Yi Shi, let's chat or why don't you tell me something," but she just kept silent. My husband and I have really tried everything we can to communicate with her, but she is still the same. I can't work out why she's so autistic, it looks like she can't find the words or she doesn't have anything to talk about. This is what she's like now.

Q: Does her brother have a girlfriend?

Shi's mother: No, my son hasn't reached that age yet, even though we encourage him to find a girlfriend. He isn't a mature boy.

Q: Do you take Yi Shi out at the weekend?

Shi's mother: Sure, sometimes, but we don't go on trips very often. We usually have a family holiday every year. Last year we went to Zhangjiajie. We can't take a holiday very often because of everybody's busy schedule. My husband has a full-time job, I'm very busy as well, and my son is in his last year at college and probably has more free time than before, so it isn't very easy for the family to go out somewhere together very often.

Now my daughter doesn't like to go out anymore, even though I'd like to take her somewhere. People tell me, you should take your daughter out more often, Japan is a good destination for her. I like the idea of going to Japan with Yi Shi, but I wouldn't like her as a companion. It would be a difficult experience; can you imagine a traveling partner never talking to you even at meal times? It doesn't motivate me!

Q: Where do you usually go with Yi Shi? 
Shi's mother: We usually go to the park or the karaoke hall. When I go out with my friends from school, they usually ask me to bring along my daughter; she used to join us for meals or singing. Sometimes, if both of us were free, I'd take her to the Shanghai Song City KTV to have some fun. I've asked her to come with me again if we get a chance in the next week or so.

My daughter is a great singer and has several MP3 and MP4 players; now her dad just bought her a tablet. She keeps a lot of songs on the tablet, and she is always playing different songs at home; she even knows more songs than us, that's pretty good? She doesn't have any musical talent, but she really likes to sing. I have to say, it's her one big hobby and it's something that also interests me.

Q: What about her relationship with her paternal grandparents?

Shi's mother: Her grandpa passed away and her grandma is now in her eighties. My daughter and I visited her last week; she isn't very close to her grandma. Yi Shi doesn't have a deep affection for my mother-in-law because she has never lived with us since my daughter was born. My son is the same, he knows her, but there is no real affection.

Q: How is Yi Shi's relationship with her maternal grandparents, then?

Shi's mother: It's not bad. My parents live just downstairs, in the same building. We are on the sixteenth floor and they are on the ninth floor. I go to check on them every day because they're over 80 years old; I worry about them even though they have a nanny to look after them. I worry who's going to take care of them when the nanny goes home for spring festival.

Q: How many siblings do you have?

Shi's mother: I only have an older sister and Yi Shi's dad has two siblings but one of them passed away. We don't live together; everybody's busy and hardly have the time to meet up or talk to each other. When my daughter was young, she used to play with her paternal cousins and they were quite close, but now she's autistic she's stopped seeing them.

To be honest, the siblings aren't that helpful even when you need them. When my children were younger and we needed some help, my sister wasn't able to help me at all because she had to work and look after her own child. So, whatever I'd hoped for, I was always on my own. Both sets of parents couldn't help me raise either of the children.

Q: What is your daughter's attitude towards others?

Shi's mother: She doesn't care much about other people. When we eat out together, she's pretty relaxed, she never bothers other people, just concentrates on her food.

Q: Does your daughter ever show any concern for you; even though she doesn't communicate with you very much?

Shi's mother: Yes, she does, for example, when we have a meal together, she usually hands you a napkin, we never taught her to do this. Even though she doesn't always remember to hand you a napkin, she is mostly very good natured. My daughter's behavior is much nicer compared to some of today's self-centered children.

Q: What do you think is Yi Shi's best characteristic, or what would you say is her good side? 
Shi's mother: My daughter is a very kind girl. Actually, all of the children like her. The children of the Sunshine Home are simple minded and nice. They never embarrass you, cheat or trick you, and they have a natural desire to help people. In this respect they can be better than many children without disabilities.

Q: Could you give me some examples?

Shi's mother: My daughter's classmates always help her with learning issues. Yi Shi doesn't talk to people very much and has a bad memory, so she can't or doesn't want to tell me about her homework or the next day's schedule.

But her classmates usually send me WeChat messages to remind me what she needs to take to school, what time she should be there, or let me know that she has notes that I have to read, or something else I should know. These children help my daughter a lot.

My daughter is a caring person, too. I had a knee joint fracture after I fell down in 2008; she was my carer during the time I had to lie down in bed, she would bring me water or clean the house, and she never complained. She also chatted with me, checked I was feeling okay, she helped with the pain and the pressure.

She looked after me for over a week until her teacher called to ask why she'd been absent for so long. The teacher was full of praise when I explained what had been happening. She said: "Yi Shi is great, she can even look after her mother now!" She also said she would come and see us, but I felt embarrassed about this and sent my daughter off to the home afterwards.

I was moved by her; she took on some difficult tasks that even normal children would be reluctant or refuse to do and she didn't have any complaints. Maybe one day she will be able to care for me when I'm very old. She isn't a troublemaker and very easy to look after at home, except she needs me to cook for her. She's pretty independent in other ways; she takes a shower or washes her hair on her own. Her only problems are that she doesn't have a good sense of value about money and she isn't good at cooking. Really, she isn't any bother at all.

\section{More Social Tolerance and Better Policies}

\section{Q: Have you thought about her and marriage?}

Shi's mother: No, we never think about this, she'll be with my husband and me wherever we go. If she's lucky and dies before us that will be fine, if it's the other way around, we'll have a plan for her. We don't worry about our son too much, one day we'll give him this apartment and let him live his own life.

Q: What's your plan for Yi Shi when you get old?

Shi's mother: We don't have a clear idea, because we don't have many choices; some parents, especially those with just a disabled child, are very anxious about this already. My husband and I are in a better situation because we also have our son. Most parents at the Sunshine Home only have one child; as well as looking after the child, they also have to look after their parents; nobody knows who will look after them or the child in the future. 
I've heard there's a special care home for special children in Chuansha Town-it's quite far away from our place - a disabled institute that opened several years ago. In the beginning, they struggled to enroll a decent number of children, but now it's full and short of places. There are quite a number of people on the waiting list already, so we'll think about where she can go later; a nursing home is another choice.

In our family, I'm the one with a short temper who might criticize her from time to time, but her dad is very tolerant. He used to tell me: "We have to give her a happy life, try our best to be tolerant and protect her, even though we can't see what might happen in the future."

The government needs to set up more disabled people's nursing homes and provide places for all of these children for the time when their parents can't look after them anymore. But I'm reluctant to send my daughter to a place now, because that will mean the end of a productive life for her. These places don't provide teaching, social events, or better care services, but they get three meals a day.

If she stays with us, at least we can talk to her every day. Her dad bought her a book of Three Hundred Tang Poems, so she can read through the book and practice her handwriting in her own time, but who would think about this kind of thing for her if she went to live in a nursing home? When the government sets up new disabled nursing homes, they have to develop the facilities, offer a higher quality service, and give more attention to the children's development.

There are some poor children who are suffering from both intellectual and physical disabilities who have no life skills of any kind. There's a boy I know in this situation, he's a very big boy, his dad has to carry him to his wheelchair and put him in before he goes to work. The child has to stay in his wheelchair all day, every day. The family had an hourly paid maid to go and clean up his room and do the housework. She'd buy him some steamed bread if they didn't have anything to eat at home. He can't look after himself at all, but at least he can speak, so when his mom came home, he asked her to pay the maid for the steamed bread. What can you do if you have a child like this? Of course, everybody wants a healthy child, but things can go wrong. These children could have a very miserable future.

Q: Do these children receive some kind of allowance or service from the government?

Shi's mother: Only unemployed children receive an allowance. If some mildly disabled children have a job, then they won't get any money. But 2 months ago, Shanghai implemented a new policy to let all disabled people receive a 150 -yuan benefit every month. In addition, if they go to a park or tourist attractions with an admission charge — some of them can be quite pricey-with a disabled card, they will let these children in for free. It's a kind of benefit as well.

Q: What are your future plans for the family?

Shi's mother: We don't expect too much, we just want our children to be healthy, for our son to do well, and one day for our daughter to enjoy her life. For me, a happy, safe and harmonious family life is the most important thing.

Q: Do you have any advice for other Down syndrome children and their families?

Shi's mother: I would say to these parents, please treat your children well and don't look down on them, because they have lives just like you and me. The truth is 
you mustn't expect too much from these children. I said the same thing to my son; he has to treat his sister well, especially because she is the reason I brought him into the world. If my daughter was a child without disability, the one-child policy wouldn't allow us to have had him.

These days I meet so many nice volunteers through some events. There's a friend who volunteered for one of our events; he is also the classmate of Pubajia, both of them graduated from Shenyang Conservatory of Music. We have a pretty good relationship. He would say to me, please let me know if Yi Shi needs my help, I'll try my best to help her. These days, there are more kind people than in the past when some people would discriminate against them. Now, most people are more open and have more sympathy towards these children. Let's be honest, none of these children chose to be disabled, everybody wants to be a healthy and able person, but fate decided against them and they have never had any choice. I urge other people to be tolerant and understanding towards them.

Q: It's the end of the interview, and I'd like to ask if we can use Yi Shi's name in the article or would you prefer her to be anonymous?

Shi's mother: I have no problem with you using her real name, that's fine. After all these years we don't care about other people's attitude towards us anymore; we are comfortable with who my daughter is.

My daughter is good at sign language dancing — would you like her to perform $A$ Grateful Heart for you? Yi Shi, could you perform it for us?

(Yi Shi remembers the lyrics very well and she's singing alone with the music. Her performance is very delicate and fluent. There is a sweet smile on her face all the time throughout the show.)

Q: Thank you very much for the interview, let's end it here.

\section{Interview with Miss Yi Shi's Younger Brother}

Interviewees: Yi Shi's mother and Yi Shi's brother

Interviewer and writer: Mengying Yang

Interview date: October 27, 2016

Interview place: Yi Shi's home

Q: How do you and your sister get on?

Shi's brother: I don't talk to her very much, it's kind of mutual. If I think about, we definitely haven't spoken more than ten sentences to each other, maybe even less than five, for some time. I won't to try to make conversation with her, and she doesn't talk to me either. It would be unusual if we spoke more than a couple of times. I want to communicate with my sister, but it never works, I guess because we don't have enough things in common to talk about.

I don't have anything to say when someone talks about my sister's condition, probably because we grew up together.

Q: Do your classmates and friends know your sister? 
Shi's brother: My current classmates don't know about her and I'm not sure if my high school classmates knew or not, but my middle classmates definitely knew, some of them even mentioned her to me. I don't know how they knew about our family.

Shi's mother: His classmates knew Yi Shi because some of them came to our place to play with my son quite often. Both of my son's primary and middle schools were close to home, and his old classmates used to come to our place.

Q: Are you worried about what their attitude might be towards your sister?

Shi's brother: I was when I was young, but not now. In the past, perhaps, but it doesn't bother me anymore.

Shi's mother: He can deal with the situation because they grew up together. I won't let him look after his sister in future because he has his own life to live. Yi Shi is my husband's and my responsibility; I won't force this responsibility on him. If my son was a girl, he might take care of Yi Shi, but one day he'll get married and his wife's attitude towards my daughter could be problematic. For a brother to look after a disabled sister, his wife would need to be a kind and caring person.

So, Yi Shi will live with us wherever we go in the future. During the National Day holiday, my husband and I bought two big apartments on the same floor in Haimen Town. We'll move there when we're old. I don't worry about my son very much, we'll give him this apartment and let him get on with his own life. Maybe one day we'll move to a nursing home with my daughter, we're not sure yet.

Q: Do you ever hang out with your sister?

Shi's mother: That's not possible, on the one hand they don't communicate with each other; on the other, my son is always busy. It's more likely that my daughter and I will go out together.

\section{Interview with Miss Yi Shi's Teacher}

Interviewee: Yi Shi's teacher at the Sunshine Home

Interviewer and writer: Mengying Yang

Interview date: October 16, 2016

Interview place: The Sunshine Home in Shanghai

(The teacher is interviewed while the other teacher, Ms. Lu shows the children how to make things with beads.)

Shi's Teacher: Teacher Lu teaches two students at a time, hand by hand, step by step, she only calls for the next pair of students when they have learned the skills properly. The two students who are being taught by teacher Lu are pretty good and can already do some things on their own. Yi Shi has the ability to make some good things with the beads, she just doesn't want to do it.

Q: When did Yi Shi come here?

Shi's Teacher: Around the end of 2013 and the beginning of 2014. She was no different to today, silent, wouldn't talk, and wouldn't answer other people's questions. She just shakes her head and nods to communicate with other people and she isn't very willing to speak to the teachers either. 


\section{Q: Can Yi Shi work with beads?}

Shi's Teacher: Yes, she can do a little bit, but her poor eyesight makes it difficult for her. She stops after she makes too many mistakes. She isn't a sociable person; she doesn't like to speak to her classmates and teachers. We asked her mother about her behavior at home and she said Yi Shi hardly talks to her family. Yi Shi always closes the door of her room when she gets back home and stays inside by herself all the time. She can't understand the teachers' words properly; for example, if you ask her: "How are you doing?" She won't understand the question, and if she answers it doesn't mean very much, she might just say something in response to your question.

This child is so difficult to communicate with, I really can't understand why. Yi Shi isn't like most of her classmates who like to chat with the teachers. When the teacher says something, the other students usually get quite excited, but she is different. It seems she lives in another world. Sometimes, she sits there and giggles for no reason. We realized that her behavior was different after she had been here for a while and we guessed she might have a problem hearing imaginary voices, she thought somebody was talking to her. But if this is true, her problem is more profound than an intellectual disability.

At the same time, Yi Shi has strong interests, she loves singing and dancing. Even when the teacher gives her a chance to sing or dance, sometimes she won't join in the group performances; but at other times she looks very excited and willing to join in the performance. Her behavior is based on her own free will; the teachers can't control her mood or responses.

Q: Teacher Wu just told me that Yi Shi hasn't been doing well recently.

Shi's Teacher: You're right. She went to the hospital with her mother, it seems she has some auditory hallucinations or some symptoms of this kind. (A student walks into the room and the interviewee starts to talk about him.) He just learned the bead-making skills from Teacher Lu as well and was Yi Shi's classmate in the past. Compared with Yi Shi's, this boy's condition is much better.

Q: Yi Shi's mother said after she's had been at home for 2 years she became unwilling to talk to other people.

Shi's Teacher: I don't know very much about this, and I don't know much about her condition either. The Sunshine Home Project only started 10 years ago. We have some students who are older than Yi Shi, in their mid-thirties now, who have been at the home even longer than her, but they don't have the same problems. This cohort of students were in their twenties when the Sunshine Homes were set up. They started primary school at six. After the 9-year compulsory education, they were 15 more or less; they then had to spend 3 years at a vocational school and were 18 years old by the end of that. After that, they had to stay at home until they were 25, more or less, before they came to a Sunshine Home, but none of them that I know had a problem like Yi Shi. The student I just mentioned, Yi Shi's old classmate, he joined the Sunshine Home later than her and he's doing very well. I can't even tell what kind of problems she has; it's definitely an individual problem, not a common phenomenon.

We don't know Yi Shi's past history very well; all of that information comes from her mother. She said her daughter was a very active and open child, but it's very hard for us to imagine what she used to be like from her present condition. None of our 
teachers had seen her before, we feel so sorry for her. Some of our students rarely talk at home, but after they join us, they become more willing to communicate with the teachers. But Yi Shi is totally another story.

Q: How many students do you have?

Shi's Teacher: We have 25 students with all kinds of intellectual disabilities. Some of them are the same as Yi Shi, Down syndrome children, some were born prematurely, some have a low IQ. But almost all of them are in the mildly disabled category. Some children have a more serious condition that might be considered as moderate to severe, grade III, or disability.

Q: It's great that the Sunshine Home provides these children with a place to stay after they leave school.

Shi's Teacher: You're right, the Sunshine Home provides some rehabilitation training classes and events to help with their self-development; also, it's a place where they can keep in touch with the world and it stops them being dumped by society. We have all kinds of activities and events; we also invite volunteers to come and deliver special classes and training; bead-making is one of our skilled training classes.

Our children only develop their skills, we don't have a way to sell what they make and very few people know about or buy their DIY products. But promotion isn't part of the Sunshine Home's duty. Basically, we're an NGO group and can't carry out commercial transactions. Also, we don't teach the students skills for making money, but create practical and learning opportunities for them; for example, the bead-making work isn't only good for their eyes, but also for their coordination.

We also have music, drawing, and culture classes and Special Olympics related sports classes. Additionally, we have an open class for them as well; in this class, if anybody wants to share something with his/her classmates, then they can do it here. After the applicant has submitted their topic and material to the teacher, he/she will receive a special tutorial to help him/her to work out how to make and deliver the presentation. After the class, the teacher will also do a presentation and discuss this with the student, giving him/her some feedback about the quality and delivery of their presentation, and how to develop their public speaking skills. It's a good way to develop social skills and help them to build their self-confidence.

The children feel care and love from society through our external volunteers who come here to help with some activities. Usually, before these volunteers leave, our children will give them some of their handmade gifts as a mark of gratitude. The reason we let them to do this is we want them to think that a disabled person's gifts, like other people's, are a natural expression of gratitude. Nothing is taken for granted. They have to try to do something for society and other people while they receive care and love from other people.

Q: Do you have any other classes?

Shi's Teacher: We have five main classes in our teaching curriculum. From Monday to Friday, we have an open class, music, artistic expression, bead-making, and an integrated class. The integrated class includes handicraft, drawing, and cooking. The drawing is a part of an ongoing module after we finish the teaching schedule. We have handwriting classes on Monday and Wednesday afternoon, Special Olympics related 
sports on Tuesday afternoon, and games time on Thursday afternoon. Games time is their free time, allowing them to play games and rest after the highly structured studying schedule.

Friday afternoon is clearing-up time; we let them clean up the classroom on their own, it's also a way to cultivate life skills. The same afternoon, there is also an hours safety education from 2 to 3 p.m. The teachers believe this aspect of education is very important for the children. We use this time to teach them some basic safety awareness, what they should be aware of when they go outside, how to deal with a call from a stranger, how to deal with a change in the weather, and so on. It's a good way to prepare them for the weekends.

Q: In which classes does Yi Shi perform better?

Shi's Teacher: She usually likes to practice her handwriting, but she doesn't play any games with her classmates. She won't refuse to join the cleaning group if you ask her to do something. She seems to like the dancing class more than music. She doesn't like to be a part of the open class or bead-making; she isn't very active in the drawing class. But she likes the artistic expression class because it includes percussion and dancing.

Q: Does she interact with her classmates?

Shi's Teacher: No, not at all. It's why we feel so sorry for her. Her mother said at home she always locks herself in her room and doesn't communicate with her parents either. I don't want to blame her parents, but for a child in this situation, the parents have to act as soon as possible and shouldn't be taking 2 years to do something. We are just her teachers and don't know her very well. When she arrived here, nobody knew her condition and background, and we couldn't communicate with her very well at all. And still, after such a long time, she hasn't improved.

We've looked for reasons and we've tried to sort out any mistakes that we could have made trying to communicate with her, like our method of communication, or our style of communication, or our speaking style. But we couldn't find anything that we could have done better. We have tried several different ways to approach communicating with Yi Shi.

We've tried approaching her through her hobbies, letting her be the principal dancer of our show at the National Day Disabled Person's performance, but that didn't work. Another time, a teacher let her participate in an ad-libbing show, dancing to the song Wahaha at a district event, but she hasn't changed at all.

We also talked to her parents about this problem, asked them to pay more attention to their daughter; on the one hand she only spends some of the day at the home, as her teachers, we aren't able to get to know her any better; on the another hand, there are many students here and everybody needs attention, we have to treat them equally. Her mother told to us, they are concerned about her condition all the time, but she always locks everybody out of her room, and doesn't want to be with the family. There aren't many more things they can do.

In the office, some teachers have discussed her case privately; firstly, the parents should have sent her here earlier, right at the beginning when they first saw signs of problems. Secondly, they should have paid more attention to her problem in the early stages; for a child like her, they need to make more effort than with their normal 
child. One day, their normal child will be independent but Yi Shi won't be; her entire life depends on her parents. Personally, I think her parents could do better than this.

$\mathrm{Q}$ : Thank you for the interview.

\section{Interview with Miss Yi Shi}

Interviewee: Yi Shi

Interviewer and writer: Mengying Yang

Interview date: October 16, 2016

Interview place: The Sunshine Home in Shanghai

(Yi Shi doesn't like to talk, she doesn't have any friends at the Sunshine Home either. She sits alone. For the interviewer's questions, she only replies with body language, nodding her head or shaking her head, or she answers with some simple words like "Yes" or "No" or "I don't know." Yi Shi seems to live in her own world except for answering questions or occasional eye contact with the interviewer.)

Q: Hi, do you remember me? I've been to your home before.

Shi: Erm...

Q: Do you remember anything about the time when you studied at the special school in the Pudong New Area?

(She shakes her head.)

Q: Did you have any friends when you were a student?

Shi: No.

Q: Have any of your classmates ever visited you?

Shi: No.

Q: Your mom told me some of your old classmates used to come around to your home because your place was nearby. Once, one of your classmates stole your mom's purse, is that true?

Shi: Yes.

Q: Do you remember what happened afterwards?

Shi: I don't remember anymore.

Q: Which grade were you when this happened?

Shi: I don't remember.

Q: What was your favorite class at school? Music class?

Shi: Erm.

Q: I saw the picture of you when you were the presenter of a school show, when I visited you last time. Is that right?

Shi: Erm.

Q: Can you remember what that show was?

Shi: I can't remember.

Q: Your mother told me that you were very open and active; you liked to chat with people. You used to give the teacher kisses and hugs every school day, didn't you?

Shi: Erm. 
Q: When did you stop talking to people? Did it happen after being at home for 2 years?

Shi: Erm.

Q: Why, is it because you don't see other people very much anymore, and don't like talking to people?

Shi: Erm.

Q: Except for the teachers, classmates, friends and parents, do you see any other people?

Shi: Erm.

Q: Do you remember the Special Olympics Game?

Shi: Erm.

Q: I saw your pictures, the ones of you and the My Hero singers taken at the television station. Do you remember this?

Shi: Erm.

Q: Do you remember who you took pictures with?

Shi: I don't remember.

Q: Were you happy being part of Special Olympics?

Shi: I was happy.

Q: Do you remember when you first came here?

Shi: I don't remember.

Q: Were you nervous when you went to the Sunshine Home for the first time?

Shi: ...

Q: Did you come with your mom?

Shi: Erm.

Q: I heard you could walk to the home on your own after she taught you how to find your own way?

Shi: Erm.

Q: How did your mom teach you to remember the route from your home to here?

Shi: I don't remember.

$\mathrm{Q}$ : Didn't you need to cross the road on the way here?

Shi: Erm.

Q: Were you worried when you walked to the home by yourself for the first time?

Shi: I wasn't worried.

Q: You were very brave. Were you nervous when you came to the Sunshine Home on the first day?

Shi: A little bit.

Q: Do you remember what you did on that first day?

Shi: I don't remember.

Q: Do you need your mom to wake you up in the morning?

Shi: I get up by myself.

Q: Do you need an alarm?

Shi: No, I don't.

Q: Your mom told me you're quite an independent girl; you can take a shower by yourself and wash your own clothes as well. Is that right?

Shi: Erm. 
Q: Do you remember when you learned these skills?

Shi: I don't remember.

Q: Do you remember how to hand wash clothes? What do you usually do?

Shi: I don't remember.

Q: Do you need your mom to remind you when to go to school: "Yi Shi, it's time to go to the Sunshine Home"? Or do you just go when the time is right?

Shi: Mom.

Q: What does your mom put in your bag before you go out?

Shi: The keys and some paper tissues.

Q: Do you prefer coming to the Sunshine Home or the school where you were before?

Shi: I like them both.

Q: What do you like to do at the Sunshine Home?

Shi:...

Q: Do you like listening to music?

Shi: I like that.

Q: Do you like anything else apart from music?

Shi: I like dancing.

Q: Do you have any favorite teachers?

Shi: ...

Q: What's your favorite class?

Shi: Music.

Q: Do you do things in any other classes apart from the music and dancing? Do you like the drawing class?

Shi: I like that.

Q: What do you like drawing?

Shi: Animals.

Q: What kind of animals?

Shi: Birds.

Q: Do you like the pottery class? I saw the mugs you made, quite pretty.

Shi: No, I don't like it.

Q: Are there any other handicraft classes you don't like?

Shi: Erm.

Q: Do you like to go and chat with your classmates?

Shi: I don't do that.

Q: Do you just sit here alone?

Shi: ...

Q: You don't like to chat with other people?

Shi: Erm.

Q: Do you prefer to come here or to stay at home?

Shi: I like to stay at home.

Q: Do you like to be alone?

Shi: Erm.

Q: Do you like other people talking to you?

Shi: I like that. 
Q: So, you do like other people talking to you?

Shi: Erm.

Q: But why don't you talk to other people? Is it because you don't know what to say to them?

Shi: Erm.

Q: Do you talk about how you feel to your mom?

(She shakes her head.)

Q: Your teacher told me you haven't been great recently. I remember you were pretty good when I visited last time and you also performed for us. What happened?

Shi: ...

Q: Why don't you make beads? You don't like that?

Shi: I can't do it.

Q: Didn't Teacher Lu teach you how to make beads?

Shi: Erm.

Q: Could you make things with beads after the teacher taught you?

Shi: I could a little bit.

Q: So, you don't like making beads, right?

Shi: Erm.

Q: You just had a bead-making class recently, can you still do that?

(She shakes her head.)

Q (asks Yi Shi's classmates who are sitting around): Does Yi Shi chat with you often?

Classmate: She's always on her own, no classmates, no friends.

Q (asks Yi Shi's classmates who are sitting around): Has she been like this since she joined the class?

Classmate: Yes, she just likes to be alone.

Q: Your mom said you worked for a while, right?

Shi: Erm.

Q: What did you do?

(She shakes her head.)

Shi: ...

Q: Your mom said you like listening to music at home?

Shi: I like writing.

Q: Anything else you like doing at home? I remember you did some handwriting for us when I visited you last time; your handwriting is very beautiful. Do you like doing anything else apart from listening to music and writing?

Shi: ...

Q: I remember your mom said your main subject at the vocational school was cooking, do you cook for your family at home?

Shi: I do.

Q: What dishes can you cook? Fried tomato and egg?

Shi: Vegetables.

Q: You can cook vegetable dishes, have you cooked it for your parents?

Shi: No.

Q: Do you remember how to cook vegetable dishes? 
Shi: I don't remember.

Q: Do you go out with your parents when you have free time?

Shi: No.

Q: Do you like to go out to the park with your mom and classmates?

Shi: I like that.

Q: Do you remember where you went last time?

Shi: I don't remember.

Q: Where do you prefer to go?

Shi: Park.

Q: What do you usually play in the park?

Shi: ...

Q: Who do you go to the park with more often, your mom or your classmates?

S Shi: Mom.

Q: Last Friday you went to a meeting with your mom, what did you do there? Did you have a happy time?

Shi: I was happy.

Q: What did you go there for, an event?

Shi: Yes.

Q: Do you remember the name of the event?

Shi: ...

Q: How do you get on with your brother?

Shi: Good.

Q: Does your brother treat you well?

Shi: Erm.

Q: Do you talk to your brother often?

Shi: Not very often.

Q: Do you and your brother just do your own things at home?

Shi: Erm.

Q: Do you talk with your mom often?

Shi: Not very much.

Q: Last time, your mom said your dad doesn't come home very often, but you're usually very happy when he does, you like to give him hugs as well. Do you like your dad?

Shi: Erm.

Q: Who do you like more, Dad or Mom?

Shi: Dad.

Q: Why's that?

Shi: ...

\section{Observation of Miss Yi Shi at the Sunshine Home}

Observation date: December 16, 2016

Observation place: The Sunshine Home in Shanghai 
Observer and writer: Mengying Yang

(The Sunshine Home's timetable had been changed and the observation only went for half a day.)

\begin{tabular}{l|l|l}
\hline Time & Content & Observed activities \\
\hline $9: 13$ & Yi Shi arrives & A classmate asks Yi Shi to sign in \\
\hline $9: 14$ & $\begin{array}{l}\text { Practicing the eighth setting-up } \\
\text { exercises and the dance Most Dazzling } \\
\text { Folk Style }\end{array}$ & $\begin{array}{l}\text { Yi Shi remembers all the movements. } \\
\text { Her performance is fluent compared } \\
\text { with her classmates, she's pretty good }\end{array}$ \\
\hline $9: 15$ & $\begin{array}{l}\text { The bead-making class starts. It's one } \\
\text { and a half hour simple handicraft class } \\
\text { The students use beads to make phone } \\
\text { cases and animals. The aim is to } \\
\text { develop their hand-eye coordination }\end{array}$ & $\begin{array}{l}\text { Yi Shi and the other students have } \\
\text { been taught by Teacher Lu before, so } \\
\text { this time she and another student sit at } \\
\text { another desk while the teacher is } \\
\text { teaching somebody else }\end{array}$ \\
\hline 9:35 & $\begin{array}{l}\text { Making beads } \\
\text { 11:00 }\end{array}$ & $\begin{array}{l}\text { Through the class, until the end, Yi } \\
\text { Shi sits alone and doesn't do anything } \\
\text { or move while the other students are } \\
\text { working with beads }\end{array}$ \\
\hline time class is finished, then it's lunch & $\begin{array}{l}\text { A teacher brings the meals to the } \\
\text { room, but Yi Shi doesn't leave her } \\
\text { seat, so a classmate fetches her lunch } \\
\text { for her }\end{array}$ \\
\hline 11:00-13:30 & Break time & $\begin{array}{l}\text { Yi Shi and her classmates are having } \\
\text { lunch in the classroom }\end{array}$ \\
\hline
\end{tabular}

Translated by Huili Meng Edited by Russell Murray

Open Access This chapter is licensed under the terms of the Creative Commons AttributionNonCommercial-NoDerivatives 4.0 International License (http://creativecommons.org/licenses/bync-nd/4.0/), which permits any noncommercial use, sharing, distribution and reproduction in any medium or format, as long as you give appropriate credit to the original author(s) and the source, provide a link to the Creative Commons license and indicate if you modified the licensed material. You do not have permission under this license to share adapted material derived from this chapter or parts of it.

The images or other third party material in this chapter are included in the chapter's Creative Commons license, unless indicated otherwise in a credit line to the material. If material is not included in the chapter's Creative Commons license and your intended use is not permitted by statutory regulation or exceeds the permitted use, you will need to obtain permission directly from the copyright holder.

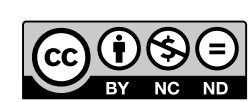

